\title{
Determinants and influencing mechanism of outpatient satisfaction: a survey on tertiary hospitals in the People's Republic of China
}

This article was published in the following Dove Press journal:

Patient Preference and Adherence

21 April 2016

Number of times this article has been viewed

\author{
Wenya $\mathrm{Yu}^{1, *}$ \\ Meina $\mathrm{Li}^{1}, *$ \\ Chen Xue ${ }^{1, *}$ \\ Jingrui Wang' \\ Jiazhen Liu² \\ Haiping Chen' \\ Lulu Zhang' \\ 'Institute of Military Health \\ Management, Second Military Medical \\ University, ${ }^{2}$ Shanghai Sixth People's \\ Hospital, Shanghai, People's Republic \\ of China \\ *These authors contributed equally \\ to this work
}

Objective: Most patients in the People's Republic of China prefer tertiary hospitals when seeking medical services. The aim of this study was to assess outpatient satisfaction with tertiary hospitals in the People's Republic of China, test overall and subscale satisfaction, and explore whether sociodemographic characteristics lead to different degrees of satisfaction and whether subscale outpatient satisfaction contributes to overall satisfaction.

Methods: A closed questionnaire was given out to investigate outpatients' sociodemographic characteristics, overall satisfaction, and various subtypes of satisfaction, and a 5-point Likert scale was employed to measure the degree of outpatient satisfaction. Descriptive analysis, Kruskal-Wallis test, Spearman's rank correlation coefficient, and logistic regression analysis were employed for statistical analysis.

Results: Response rate was $92.48 \%$ (971/1,050). Outpatients' sociodemographic characteristics (including sex, age, occupation, monthly income, residence, and marital status) were related to various subtypes of satisfaction to varying degrees. Outpatients who were male, older, married, with low or middle incomes, living in Shanghai or other areas of the People's Republic of China, medical staff, or students were more satisfied with various subtypes of satisfaction than those without these characteristics. In further analyses, satisfaction with their medical needs being met by doctors had the strongest relation to overall satisfaction, followed by satisfaction with doctors' service attitudes, medical costs, waiting time, prescription, and diagnosis and treatment time. Satisfaction with environment had the weakest contribution to overall satisfaction.

Conclusion: This study gave some suggestions for tertiary hospitals in advanced areas of the People's Republic of China. Outpatient sociodemographic characteristics should be paid more attention by medical staff to improve the degree of satisfaction. Tertiary hospitals in the People's Republic of China should provide more support on the management of doctors, medical costs, and time.

Keywords: outpatient satisfaction, tertiary hospitals, sociodemographic characteristics, influencing factor

\section{Introduction}

Patient satisfaction refers to the degree of conformity between patients' expectations and the reality regarding their experience of medical services, the quality of received health care, feelings related to diagnosis and treatment, and consensus about the treatment program. ${ }^{1,2}$ In other words, it is a reflection of patients' perceptions of medical care processes, and it is considered an important index of medical quality. ${ }^{3,4}$ Outpatient services - which represent an entry point for medical services - can directly influence patients' satisfaction. ${ }^{5}$ In 2010 , The Lancet reported on the extremely poor-quality 
of doctor-patient relationship in the People's Republic of China. ${ }^{6}$ Within this background, research on outpatient satisfaction in the People's Republic of China is of considerable importance.

Research on patient satisfaction abroad originated in customer satisfaction surveys conducted in the 1970s. ${ }^{7}$ To date, most of this research has explored the factors influencing various types of satisfaction; more recently, studies have begun focusing on how to maximize the satisfaction of various subjects (eg, patients and medical staff) ${ }^{8,9}$ with different topics (eg, services and resources). ${ }^{10,11}$ Furthermore, these studies either concentrated on a given factor influencing patient satisfaction ${ }^{12-16}$ or focused on multiple factors at once. ${ }^{10,17-21}$

When drawing on the full body of literature on patient satisfaction, both domestic and abroad, factors related to patient satisfaction can be approximately categorized as patient, medical staff, and medical environment factors. ${ }^{9-11,13,15,19,20,22-27}$ Examples are presented in Table 1.

Research on patient satisfaction in the People's Republic of China began relatively later; only a few studies were carried out in the late 1980s, and it was not until the 1990s that full attention was given. ${ }^{28,29}$ Currently, the research types of most Chinese studies on patient satisfaction are theoretical studies $^{7,30}$ or survey analyses. ${ }^{31-33}$ The former is limited only to exploring the theory of patient satisfaction, whereas latter explores the influencing factors based on questionnaires.

Table I Factors related to patient satisfaction based on literature studies

\begin{tabular}{ll}
\hline Category & Factor \\
\hline Patient & Sociodemographic characteristics \\
& Disease \\
& Medical needs and education \\
& Access to medical information \\
& Participation in decision making \\
& Medical costs \\
Medical staff & \\
Doctors & Diagnosis and treatment process \\
& Medical technology \\
& Communication skills \\
Nurses & Service attitudes \\
& Quality of nursing care \\
& Service attitudes \\
Doctor-patient relationship & Length of work time \\
& Doctor-patient relations \\
& Medical care quality \\
& Doctor-patient interaction \\
Medical environment & Waiting time \\
& Hospital environment \\
& Accessibility to medical services \\
& Hospital characteristics \\
\hline
\end{tabular}

However, the majority of the previous survey analyses were conducted in only one hospital and were therefore aimed at the development of that particular hospital; thus, their results would not generalize to other hospitals. ${ }^{34-36}$

Most of the tertiary hospitals in Shanghai have a highquality patient satisfaction assessment system. Studying patient satisfaction in these hospitals would be both feasible and more representative than previous studies, given the large scale, various patient sources, and numerous types of diseases they cover. Thus, we believed that it is necessary to investigate the eleven tertiary hospitals that use this system. Our study would help tertiary hospitals in more developed areas to determine the key factors needing improvement to optimize outpatient satisfaction.

\section{Methods}

We carried out a survey on outpatient satisfaction from June 2013 to September 2013 at eleven tertiary hospitals in Shanghai. Before the formal investigation, we recruited 50 outpatients (who were excluded from the main analysis) to perform a preliminary survey. According to the results of the preliminary survey, some items were eliminated or revised because of a high nonresponse rate or poor variability. The study protocol was approved by the ethics committee of the Second Military Medical University.

In the formal investigation, of the 1,050 questionnaires administered, 971 were returned completed (valid response rate: $92.48 \%$ ). All the 971 outpatients were Chinese. They were selected at random from each hospital from different clinical departments and had varying diseases. We adopted no inclusion criteria other than the willingness to participate in the study; however, the exclusion criterion was being unable to complete the questionnaire due to a lack of cognitive function or suffering from a disturbance of consciousness, dementia, or other severe symptoms. Before they began the questionnaire, all participants gave their written informed consent; in addition, participants were assured that their privacy was guaranteed to be protected. If participants could not understand a survey item, investigators explained it to them. All investigators were professionally trained by statistics professors who were experts in administering surveys on-site; furthermore, all the received questionnaires were checked and verified by the investigators and supervisors.

The questionnaire items were adapted from the inpatient satisfaction evaluation questionnaire used in most hospitals in Shanghai. More specifically, because there is no established evaluation instrument for outpatient satisfaction in the People's Republic of China, the items were designed 
such that they combined outpatient characteristics and the outpatient treatment process with this existing inpatient satisfaction evaluation questionnaire. To demonstrate the reliability of this questionnaire, we determined its internal consistency via the Cronbach's $\alpha$ coefficient. Furthermore, the Kaiser-Meyer-Olkin test and Bartlett's test of sphericity were used to screen for factorability of the data obtained from this questionnaire. The questionnaire comprised 16 items to describe outpatients' sociodemographic characteristics and assess their degree of satisfaction. A 5-point Likert scale was employed to measure outpatient satisfaction, with response options of 1 (very dissatisfied), 2 (dissatisfied), 3 (moderate), 4 (satisfied), and 5 (very satisfied). Four dimensions of satisfaction were assessed: overall satisfaction and satisfaction with doctors, nurses, and other factors. All survey items are presented in the Supplementary material.

All the data were entered by two authors simultaneously using EpiData 3.1; data analysis was performed using SAS 8.0 and SPSS 18.0. Descriptive analysis was used to describe sociodemographic characteristics and outpatient satisfaction. The Kruskal-Wallis test or Spearman's rank correlation was used to analyze the data in a fourfold contingency table depending on the type of variable. Specifically, the KruskalWallis test was used to analyze the differences in outpatient satisfaction according to the categorical sociodemographic characteristics (including sex, occupation, residence, and marital status), whereas Spearman's rank correlation was employed to analyze the relationships between outpatient satisfaction and categorical sociodemographic characteristics (age and monthly income). Stepwise logistic regression analysis was used to analyze the relations between sociodemographic characteristics and outpatient satisfaction (both overall satisfaction and the various subtypes). In this analysis, response alternatives were categorized into five groups of "very dissatisfied" to "very satisfied" according to participants' answers on the 5-point Likert scale for outpatient satisfaction, with the "very satisfied" group as the reference. The odds ratios of having higher satisfaction among outpatients for different characteristics were determined by comparing participants with the reference group of each characteristic. If the odds ratio exceeded 1 , the patients had greater odds of having high satisfaction than the reference group. All tests were two way, and $P<0.05$ was considered statistically significant.

\section{Results}

\section{Test for the questionnaire}

The Cronbach's $\alpha$ coefficient was 0.712 , which indicates that the scale had a good internal consistency. The
Kaiser-Meyer-Olkin was 0.895, and the $\chi^{2}$ value of Bartlett's test of sphericity was $6,487.541(P<0.01)$, indicating that the factorability of the data in this survey was appropriate.

\section{Sociodemographic characteristics}

Among the 971 outpatients, $45.21 \%$ were male and 54.79\% female. Outpatients were mainly retirees $(21.73 \%)$ but also comprised workers, students, civil servants, farmers, medical staff, military personnel, and other. Age was essentially normally distributed, with the most prevalent age group being $30-39$ years (24.41\%). Outpatients mainly had middle or low income, with most having an income of 2,000-4,999 renminbi (RMB) per month, while only 5.77\% were high earners $(>8,000 \mathrm{RMB})$. Almost all participants lived in the People's Republic of China, and most lived in Shanghai $(62.62 \%)$. The majority of participants were married (74.15\%; Table 2).

Table 2 Sociodemographic characteristics of outpatients

\begin{tabular}{ll}
\hline Sociodemographic characteristics & $\mathbf{N}(\%)$ \\
\hline Sex & \\
Male & $439(45.2)$ \\
Female & $532(54.8)$ \\
Occupation & \\
Student & $106(10.9)$ \\
Worker & $160(16.5)$ \\
Farmer & $74(7.6)$ \\
Retiree & $211(21.7)$ \\
Civil servant & $79(8.1)$ \\
Medical staff & $46(4.7)$ \\
Military personnel & $19(2.0)$ \\
Other & $276(28.4)$ \\
Age (years) & \\
$<20$ & $70(7.2)$ \\
$20-29$ & $223(23.0)$ \\
$30-39$ & $237(24.4)$ \\
$40-49$ & $175(18.0)$ \\
$50-59$ & $153(15.8)$ \\
$\geq 60$ & $113(11.6)$ \\
Monthly income (RMB) & \\
$<2,000$ & $198(30.7)$ \\
$2,000-4,999$ & $475(48.9)$ \\
$5,000-7,999$ & $142(14.6)$ \\
$8,000-9,999$ & $34(3.5)$ \\
$\geq 10,000$ & $22(2.3)$ \\
Residence & \\
Shanghai & $608(62.6)$ \\
Other areas of the People's Republic of China \\
Abroad & $357(36.8)$ \\
Marital status & $6(0.6)$ \\
Married & $212(21.8)$ \\
Single & $720(74.2)$ \\
Divorced & $24(2.5)$ \\
Widowed & $15(1.5)$ \\
\hline
\end{tabular}




\section{Outpatient satisfaction}

\section{Overall satisfaction}

The mean overall outpatient satisfaction was 3.956, indicating a relatively high degree of satisfaction. Overall satisfaction significantly differed by sex $(F=16.1, P=0.0)$, occupation ( $F=4.7, P=0.0$ ), and residence $(F=7.4, P=0.0)$; specifically, the overall satisfaction of men, medical staff, and those living in Shanghai was higher than that of women, other occupations, and those living in other areas, respectively (Table 3).

\section{Satisfaction with doctors}

Satisfaction with service attitudes was the highest, while satisfaction with medical needs being met by doctors was the lowest. The mean outpatient satisfaction scores for diagnosis and treatment time and prescription were 4.053 and 4.032 , respectively. These subtypes of satisfaction differed by sex, occupation, and residence of outpatients in the same way as did overall satisfaction (Table 3 ). The effect sizes and $P$-values for service attitudes were $F=13.9$ and $P=0.0$ (sex), $F=3.6$ and $P=0.0$ (occupation), and $F=6.2$ and $P=0.0$ (residence); for diagnosis and treatment time $F=13.3$ and $P=0.0$ (sex), $F=3.4$ and $P=0.0$ (occupation), and $F=6.5$ and $P=0.0$ (residence); for medical needs $F=17.5$ and $P=0.0$ (sex), $F=3.3$ and $P=0.0$ (occupation), and $F=6.2$ and $P=0.0$ (residence); and for prescription $F=32.4$ and $P=0.0$ (sex), $F=4.4$ and $P=0.0$ (occupation), and $F=7.6$ and $P=0.0$ (residence), respectively. In addition, satisfaction with prescription significantly differed by marital status ( $F=5.4$ and $P=0.0)$, with single participants having the highest scores.

\section{Satisfaction with nurses}

Satisfaction with nurses was relatively high, with nurses both at prediagnosis counters and in the waiting room. A Kruskal-Wallis test revealed the same results as the aforementioned types of satisfaction (Table 3) regarding sex, occupation, and residence. The effect sizes and $P$-values for nurses at prediagnosis counters were $F=12.8$ and $P=0.0$ (sex), $F=3.3$ and $P=0.0$ (occupation), and $F=5.6$ and $P=0.0$ (residence) and for nurses in the waiting room $F=15.4$ and $P=0.0$ (sex); $F=3.4$ and $P=0.0$ (occupation), and $F=5.2$ and $P=0.0$ (residence), respectively.

\section{Satisfaction with other factors}

The degree of satisfaction with other factors was lower, especially satisfaction with medical costs and waiting time, than that of the other types of satisfaction mentioned earlier. Satisfaction with hospital environment, medical costs, and waiting time significantly differed by sex $(F=20.1$ and

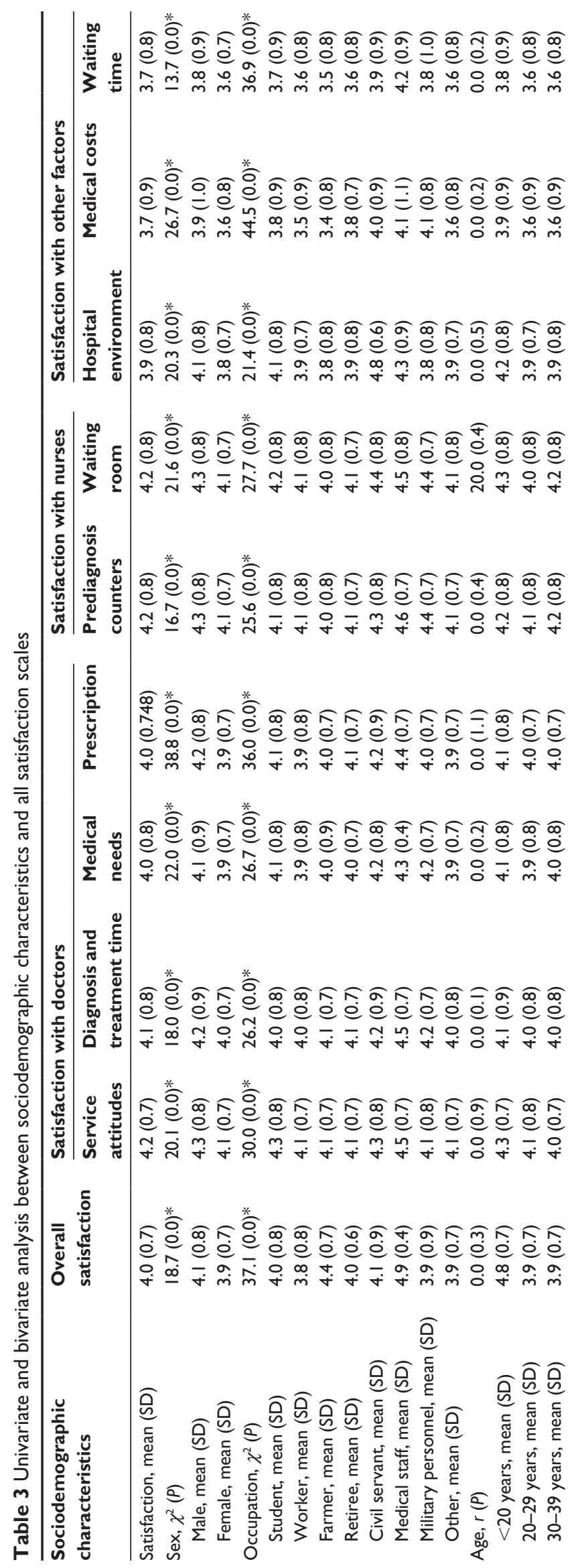


๓๐ลสิณ

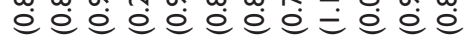

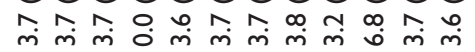

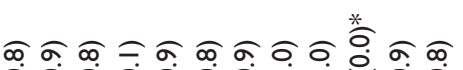

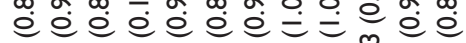

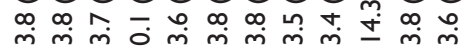

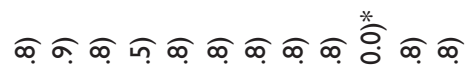

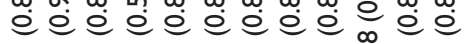

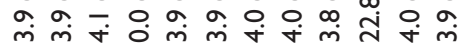

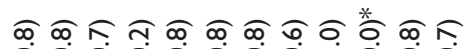

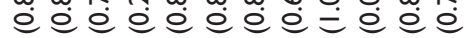

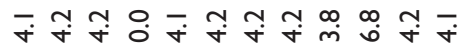

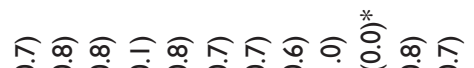

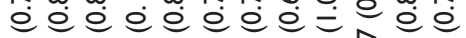
ก

कิ

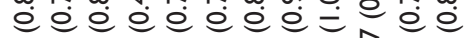

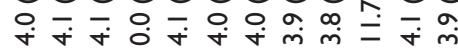

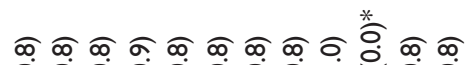

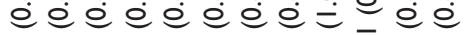

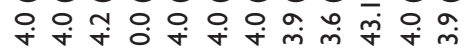

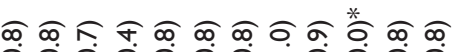

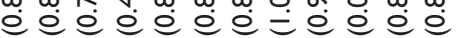

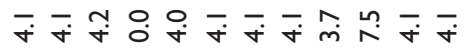

Кำ

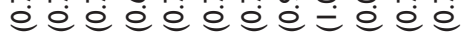
กั

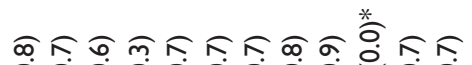

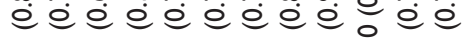

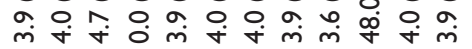

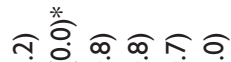 릉

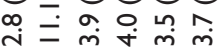

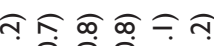 - 0 迫

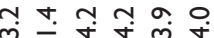

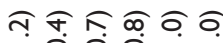

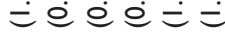
กั

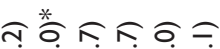
- 000

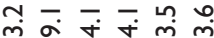

๙ิ $\widehat{\infty} \widehat{\alpha} \simeq$ -000்

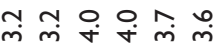

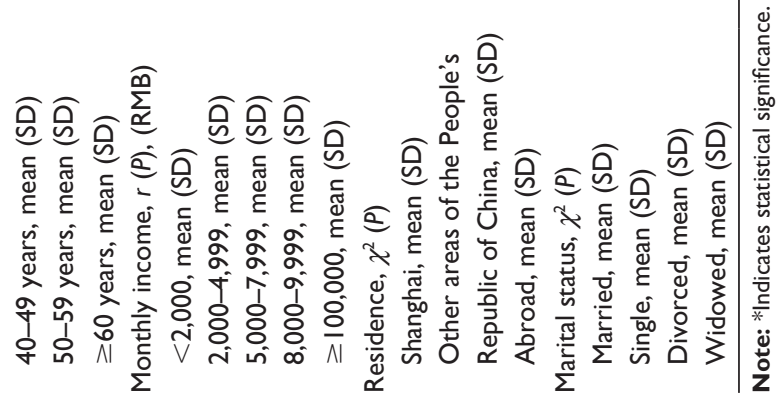

$P=0.0 ; F=23.0$ and $P=0.0 ; F=14.8$ and $P=0.0$ ), occupation ( $F=2.6$ and $P=0.0 ; F=6.6$ and $P=0.0 ; F=5.0$ and $P=0.0)$, and residence $(F=9.2$ and $P=0.0 ; F=6.9$ and $P=0.0 ; F=3.4$ and $P=0.0$ ), respectively. Furthermore, satisfaction with hospital environment significantly differed by marital status $(F=4.3$, $P=0.0$ ). Specifically, men and those living in Shanghai were more satisfied in terms of all three factors; civil servants had the highest degree of satisfaction with the environment, while medical staff had the highest degree of satisfaction with medical costs and waiting time. Satisfaction with environment was higher among single participants (Table 3 ).

\section{Relationships between outpatient satisfaction and influencing factors Overall satisfaction and sociodemographic characteristics}

According to the odds ratios yielded from the logistic regression analysis (Table 4), men, medical staff (reference: students), those with a monthly income of 2,000-4,999 RMB (reference: $\geq 10,000 \mathrm{RMB}$ ), and those living in Shanghai or other areas of the People's Republic of China (reference: living abroad) all had greater odds of high overall satisfaction.

\section{Satisfaction with doctors and sociodemographic characteristics}

Male outpatients always had greater odds of high satisfaction with doctors (ie, for all aspects of the variable) than female outpatients. Furthermore, young and middle-aged adults (20-39 years) (reference: $\geq 60$ years) generally had lower odds of high satisfaction with doctors' service attitudes, diagnosis and treatment time, and medical needs being met by doctors. Additionally, medical staff had greater odds of high satisfaction with diagnosis and treatment time. Participants who lived in the People's Republic of China (including Shanghai and other areas) had greater odds of high satisfaction with doctors' service attitudes and diagnosis and treatment time than foreigners. Furthermore, divorced or widowed (reference: married) had lower odds of being highly satisfied with doctors. Interestingly, outpatients with low- and middle-level incomes tended to have greater odds of having high satisfaction than those with high monthly incomes ( $\geq 10,000 \mathrm{RMB}$; Table 4).

\section{Satisfaction with nurses and sociodemographic characteristics}

The factors influencing outpatient satisfaction with nurses at the prediagnosis counters and in the waiting rooms were highly similar. Men, medical staff, and those living in the 
Table 4 Logistic regression analysis of sociodemographic characteristics and outpatient satisfaction

\begin{tabular}{|c|c|c|c|c|c|c|c|}
\hline \multirow[t]{2}{*}{ Logistic regression analysis } & \multirow[t]{2}{*}{ Parameter } & \multirow[t]{2}{*}{ Estimate } & \multicolumn{2}{|c|}{$\begin{array}{l}95 \% \text { Wald } \\
\text { confidence limits }\end{array}$} & \multirow[t]{2}{*}{ OR } & \multicolumn{2}{|c|}{$\begin{array}{l}95 \% \text { Wald } \\
\text { confidence limits }\end{array}$} \\
\hline & & & Lower & Upper & & Lower & Upper \\
\hline \multirow[t]{6}{*}{ Overall satisfaction } & Sex & -0.5 & -0.7 & -0.2 & 0.6 & 0.5 & 0.8 \\
\hline & Medical staff & 1.0 & 0.0 & 1.9 & 2.6 & 1.1 & 6.6 \\
\hline & $2,000-4,999$ RMB & 0.9 & 0.0 & 1.7 & 2.4 & 1.1 & 5.6 \\
\hline & Shanghai & 2.0 & 0.3 & 3.6 & 7.1 & 1.4 & 37.4 \\
\hline & Other areas of the & 1.9 & 0.3 & 3.6 & 6.8 & 1.3 & 35.3 \\
\hline & People's Republic of China & & & & & & \\
\hline Satisfaction with doctors' service & Sex & -0.5 & -0.7 & -0.2 & 0.6 & 0.5 & 0.8 \\
\hline \multirow[t]{6}{*}{ attitudes } & $20-29$ years old & -0.7 & -1.4 & -0.1 & 0.5 & 0.2 & 0.9 \\
\hline & 30-39 years old & -0.7 & -1.3 & -0.1 & 0.5 & 0.3 & 0.9 \\
\hline & Shanghai & 2.1 & 0.5 & 3.7 & 8.1 & 1.6 & 40.7 \\
\hline & Other areas of the & 2.1 & 0.5 & 3.7 & 8.2 & 1.6 & 41.0 \\
\hline & People's Republic of China & & & & & & \\
\hline & Divorced & -0.9 & -1.9 & 0.0 & 0.4 & 0.2 & 0.9 \\
\hline Satisfaction with diagnosis and treatment & Sex & -0.5 & -0.7 & -0.2 & 0.6 & 0.5 & 0.8 \\
\hline \multirow[t]{7}{*}{ time } & Medical staff & 1.3 & 0.4 & 2.2 & 3.6 & $\mathrm{I} .4$ & 9.0 \\
\hline & $20-29$ years old & -0.8 & -1.4 & -0.1 & 0.5 & 0.2 & 0.9 \\
\hline & $30-39$ years old & -0.6 & -1.2 & 0.0 & 0.5 & 0.3 & 0.9 \\
\hline & Shanghai & 1.9 & 0.3 & 3.5 & 6.7 & $\mathrm{I} .4$ & 32.5 \\
\hline & Other areas of the & 1.8 & 0.3 & 3.4 & 6.3 & 1.3 & 30.4 \\
\hline & People's Republic of China & & & & & & \\
\hline & Divorced & -1.4 & -2.3 & -0.5 & 0.3 & 0.1 & 0.6 \\
\hline Satisfaction with medical needs being & Sex & -0.5 & -0.7 & -0.3 & 0.6 & 0.5 & 0.8 \\
\hline \multirow[t]{8}{*}{ met by doctors } & $20-29$ years old & -0.8 & -1.5 & -0.2 & 0.4 & 0.2 & 0.8 \\
\hline & 30-39 years old & -0.7 & -1.3 & -0.1 & 0.5 & 0.3 & 0.9 \\
\hline & $40-49$ years old & -0.8 & -1.4 & -0.2 & 0.5 & 0.3 & 0.8 \\
\hline & $50-59$ years old & -0.6 & -1.0 & -0.1 & 0.6 & 0.4 & 0.9 \\
\hline & Unemployed & 1.0 & 0.1 & 2.0 & 2.8 & I.I & 7.4 \\
\hline & $2,000-4,999$ RMB & 1.0 & 0.2 & 1.9 & 2.8 & 1.2 & 6.5 \\
\hline & 5,000-7,999 RMB & 1.0 & 0.1 & 1.9 & 2.7 & I.I & 6.4 \\
\hline & Widowed & -1.1 & -2.2 & 0.0 & 0.3 & 0.1 & 0.9 \\
\hline \multirow[t]{2}{*}{ Satisfaction with prescription } & Sex & -0.7 & -1.0 & -0.5 & 0.5 & 0.4 & 0.6 \\
\hline & Divorced & -1.2 & -2.1 & -0.2 & 0.3 & 0.1 & 0.8 \\
\hline Satisfaction with nurses at prediagnosis & Sex & -0.4 & -0.7 & -0.2 & 0.6 & 0.5 & 0.8 \\
\hline \multirow[t]{6}{*}{ counters } & Medical staff & 1.5 & 0.6 & 2.5 & 4.7 & 1.8 & 12.0 \\
\hline & $20-29$ years old & -0.9 & -1.5 & -0.2 & 0.4 & 0.2 & 0.8 \\
\hline & $40-49$ years old & -0.6 & -1.2 & 0.0 & 0.5 & 0.3 & 0.9 \\
\hline & Shanghai & 1.8 & 0.2 & 3.4 & 6.2 & 1.3 & 30.3 \\
\hline & Other areas of the & 1.8 & 0.3 & 3.4 & 6.3 & 1.3 & 30.8 \\
\hline & People's Republic of China & & & & & & \\
\hline Satisfaction with nurses in the waiting & Sex & -0.5 & -0.8 & -0.3 & 0.6 & 0.5 & 0.8 \\
\hline \multirow[t]{7}{*}{ room } & Medical staff & 1.4 & 0.5 & 2.4 & 4.1 & 1.6 & 10.6 \\
\hline & $20-29$ years old & -1.0 & -1.7 & -0.3 & 0.4 & 0.2 & 0.7 \\
\hline & $40-49$ years old & -0.7 & -1.2 & -0.1 & 0.5 & 0.3 & 0.9 \\
\hline & Unemployed & 1.0 & 0.0 & 1.9 & 2.7 & 1.0 & 6.9 \\
\hline & Shanghai & 1.7 & 0.1 & 3.3 & 5.4 & I.I & 26.6 \\
\hline & Other areas of the & 1.8 & 0.2 & 3.4 & 5.9 & 1.2 & 29.1 \\
\hline & People's Republic of China & & & & & & \\
\hline \multirow[t]{10}{*}{ Satisfaction with hospital environment } & Sex & -0.5 & -0.8 & -0.3 & 0.6 & 0.5 & 0.8 \\
\hline & $20-29$ years old & -1.3 & -1.9 & -0.6 & 0.3 & 0.1 & 0.5 \\
\hline & $30-39$ years old & -1.2 & -1.8 & -0.6 & 0.3 & 0.2 & 0.6 \\
\hline & $40-49$ years old & -1.3 & -1.9 & -0.7 & 0.3 & 0.2 & 0.5 \\
\hline & 50-59 years old & -0.7 & -1.2 & -0.2 & 0.5 & 0.3 & 0.8 \\
\hline & 8,000-9,999 RMB & 1.1 & 0.0 & 2.1 & 2.9 & I.I & 8.1 \\
\hline & Shanghai & 2.2 & 0.5 & 3.9 & 8.9 & 1.7 & 47.3 \\
\hline & Other areas of the & 2.1 & 0.4 & 3.7 & 7.9 & 1.5 & 42.1 \\
\hline & People's Republic of China & & & & & & \\
\hline & Divorced & -1.2 & -2.1 & -0.3 & 0.3 & 0.1 & 0.8 \\
\hline
\end{tabular}


Table 4 (Continued)

\begin{tabular}{|c|c|c|c|c|c|c|c|}
\hline \multirow[t]{2}{*}{ Logistic regression analysis } & \multirow[t]{2}{*}{ Parameter } & \multirow[t]{2}{*}{ Estimate } & \multicolumn{2}{|c|}{$\begin{array}{l}95 \% \text { Wald } \\
\text { confidence limits }\end{array}$} & \multirow[t]{2}{*}{ OR } & \multicolumn{2}{|c|}{$\begin{array}{l}95 \% \text { Wald } \\
\text { confidence limits }\end{array}$} \\
\hline & & & Lower & Upper & & Lower & Upper \\
\hline \multirow[t]{3}{*}{ Satisfaction with medical costs } & Sex & -0.6 & -0.8 & -0.3 & 0.6 & 0.4 & 0.7 \\
\hline & Worker & -1.0 & -1.8 & -0.2 & 0.4 & 0.2 & 0.8 \\
\hline & $2,000-4,999$ RMB & 0.9 & 0.0 & 1.8 & 2.5 & I.I & 6.1 \\
\hline \multirow[t]{9}{*}{ Satisfaction with waiting time } & Sex & -0.4 & -0.6 & -0.1 & 0.6 & 0.5 & 0.9 \\
\hline & Retiree & -1.1 & -1.9 & -0.2 & 0.9 & 0.1 & 0.8 \\
\hline & $<20$ years old & -1.0 & -2.0 & -0.1 & 0.5 & 0.1 & 0.9 \\
\hline & $20-29$ years old & -1.2 & -1.8 & -0.5 & 0.5 & 0.2 & 0.6 \\
\hline & $30-39$ years old & -1.1 & -1.7 & -0.5 & 0.5 & 0.2 & 0.6 \\
\hline & 40-49 years old & -0.9 & -1.5 & -0.3 & 0.6 & 0.2 & 0.7 \\
\hline & 2,000-4,999 RMB & 1.0 & 0.1 & 1.8 & 2.0 & I.I & 6.2 \\
\hline & 5,000-7,999 RMB & 1.0 & 0.1 & 1.9 & 1.8 & I.I & 6.6 \\
\hline & 8,000-9,999 RMB & 1.2 & 0.2 & 2.3 & 2.0 & 1.2 & 9.5 \\
\hline \multirow[t]{7}{*}{$\begin{array}{l}\text { Overall satisfaction and various } \\
\text { satisfaction dimensions }\end{array}$} & $\begin{array}{l}\text { Service attitudes of } \\
\text { doctors }\end{array}$ & 0.7 & 0.4 & 1.0 & 2.0 & $\mathrm{I} .4$ & 2.8 \\
\hline & $\begin{array}{l}\text { Diagnosis and treatment } \\
\text { time }\end{array}$ & 0.4 & 0.1 & 0.7 & 1.4 & I.I & 2.0 \\
\hline & $\begin{array}{l}\text { Medical needs being met } \\
\text { by doctors }\end{array}$ & 1.0 & 0.7 & $\mathrm{I} .3$ & 2.7 & 2.0 & 3.8 \\
\hline & Prescription & 0.5 & 0.2 & 0.8 & 1.6 & 1.2 & 2.2 \\
\hline & Hospital environment & 0.3 & 0.0 & 0.5 & 1.3 & I.I & 1.7 \\
\hline & Medical costs & 0.7 & 0.4 & 0.9 & 1.9 & 1.5 & 2.4 \\
\hline & Waiting time & 0.6 & 0.4 & 0.8 & 1.9 & $\mathrm{I} .5$ & 2.3 \\
\hline
\end{tabular}

Abbreviations: RMB, renminbi; OR, odds ratio.

People's Republic of China all had greater odds of having high satisfaction with nurses. However, those in the age groups of 20-29 and 40-49 years were less satisfied with nurses than older adults (Table 4).

Satisfaction with other factors and sociodemographic characteristics

As with the other types of satisfaction, men tended to have greater odds of high satisfaction with the hospital environment, medical costs, and waiting time than women. Unlike the other types, however, outpatients $\geq 60$ years old had greater odds of having high satisfaction with these factors (except for medical costs) than other age groups. Furthermore, participants in the second highest monthly income group (8,000-9,999 RMB) had greater odds of high satisfaction than any other income group (including the lowest and highest groups). Occupation also played an important role in this aspect of satisfaction, with workers being more sensitive to medical costs and retirees being less satisfied with waiting time (Table 4).

\section{Relationship between overall satisfaction and various satisfaction dimensions}

According to the results of a logistic regression analysis, besides the satisfaction with nurses, satisfaction with doctors and other factors were all significantly related to overall satisfaction. Specifically, odds ratios indicated that the greatest contributor to overall satisfaction was satisfaction with medical needs being met by doctors, followed by satisfaction with doctors' service attitudes, medical costs, waiting time, prescription, and diagnosis and treatment time; outpatient satisfaction with the hospital environment contributed the least (Table 4).

\section{Discussion}

We found that, among outpatients, the highest scores were for satisfaction with nurses, followed by satisfaction with doctors and other factors. Since the beginning of the reform of the nursing profession (wherein greater emphasis is being placed on health care quality, better nurse-patient relationships, and a more comprehensive nursing process $)^{37}$ in the People's Republic of China, nurse performance evaluations have been widely applied across the country. ${ }^{38}$ These evaluations assess a number of factors, including patient satisfaction, ${ }^{39}$ and have effectively improved patient satisfaction with nurse services. ${ }^{40}$ Although community-first treatment and two-way referral systems have been in place for nearly 10 years in the People's Republic of China, their intended purpose - alleviating the burden of tertiary hospitals - has not been achieved, as patients are continuing to crowd into 
tertiary hospitals. ${ }^{41}$ To deal with this high influx, tertiary hospitals have set up "prediagnosis counters". Nurses at the prediagnosis counters perform triage, ${ }^{42}$ conduct prediagnoses to help patients register appropriately, and facilitate clinic processing, thereby effectively shortening the waiting time ${ }^{43}$ and improving patient satisfaction. ${ }^{44}$ Given these two reasons, diagnosis and treatment of outpatients have become more accurate and effective; however, the ever-increasing number of patients makes it inevitable that they will experience a longer waiting time, which can trigger higher rates of dissatisfaction. This is likely why the outpatient satisfaction with nurses in the waiting room was lower than that of nurses at the prediagnosis counters. Similar findings were noted in previous studies, wherein services provided by medical staff at the prediagnosis counters had a stronger effect on patient satisfaction. ${ }^{10}$

Outpatient satisfaction with doctors was lower than that of nurses. The doctor-patient relationship has increasingly worsened over the past decade in the People's Republic of China, and the number of doctor-patient conflicts increased by $>20$ times during that period. Of 326 hospitals surveyed, the annual average number of violent incidents increased from 20.6 in 2008 to 27.3 in 2012. Among doctor-patient dispute cases, $90 \%$ of involved patients have reported that they prefer to solve problems through violence. ${ }^{45}$ Therefore, it is understandable why outpatient satisfaction with doctors is relatively lower than that of nurses.

To improve outpatient satisfaction with doctors, hospitals have concentrated on improving doctors' service attitudes via doctor performance evaluation systems. ${ }^{46}$ This has had some benefits, with doctors' service attitudes continuing to improve over time; ${ }^{47}$ this explains why the degree of outpatient satisfaction with doctors' service attitudes was the highest among the whole scale of outpatient satisfaction with doctors. Additionally, it was explicitly stipulated in Shanghai that the maximum number of patients diagnosed and treated by a doctor every day is 40 , while the minimum diagnosis and treatment time for every patient is 10 minutes. ${ }^{48}$ Although efforts were made to ensure a more careful diagnosis and treatment process, patients cannot yet well communicate with doctors about their medical needs, feelings, or preferences. Therefore, outpatients' satisfaction with medical needs being met by doctors remains low. Furthermore, with the implementation of policies such as the cancelation of the drug addition cost (which permitted hospitals to set the retail prices of drugs at $15 \%$ more than the drug's cost) and the necessity of ordering reasonable laboratory examinations, hospitals and doctors no longer prioritize prescription of expensive drugs and examinations. However, there is still a wide gap between expectations and reality among patients, ${ }^{49}$ which explains why the degree of outpatient satisfaction with prescriptions was relatively lower than that of the other types of satisfaction with doctors (although it was still at a reasonably high level). Studies abroad have made similar discoveries - namely, that listening to the medical needs of patients can improve their satisfaction ${ }^{20}$ and that a doctor-patient communication time of $<10$ minutes can decrease patient satisfaction. ${ }^{50}$

The environments of tertiary hospitals in the People's Republic of China are constantly improving, reflecting a greater attention to humanity and ecology. ${ }^{51}$ Such an environment makes patients feel more comfortable in visiting, promotes their recovery, and ultimately improves their satisfaction. ${ }^{52}$ This is a likely reason that outpatient satisfaction with the hospital environment was relatively high; our finding is further supported by a previous study on the hospital environment. ${ }^{14}$

Additionally, the average outpatient medical costs of tertiary hospitals were 242.1 RMB in 2012, which shows that the 2012 rate of increase was a decrease of $3.66 \%$ from the 2009 rate. ${ }^{53}$ Furthermore, urban employees participating in a basic medical insurance system enjoy a reimbursement proportion of $50 \%-60 \%$ when visiting a tertiary hospital. ${ }^{54}$ The two aspects have greatly alleviated the financial burden caused by medical costs, but there is still space for improvement. This explains why the degree of outpatient satisfaction with medical costs was at an intermediate level. ${ }^{18}$

The relatively low satisfaction with waiting times can likely be explained by the high inflow of patients to tertiary hospitals, as noted earlier. Similar findings have been noted in a survey in Japan. ${ }^{55}$

Considering the contributions of various subtypes of satisfaction to overall satisfaction, results indicate that tertiary hospitals in the People's Republic of China should encourage doctors to pay more attention to the medical needs of outpatients, improve service attitudes, and further increase diagnosis and treatment time. Hospitals should gradually eliminate expensive and unreasonable prescriptions. Policies should guide patients with common diseases and slight discomforts to community health systems to alleviate the overload in tertiary hospitals and effectively shorten outpatients' waiting times. Meanwhile, the government should vigorously enforce the cancelation of drug addition cost and increase the proportion of reimbursement of medical insurance to greatly reduce outpatients' medical costs. Previous studies have drawn similar conclusions: perceptions, waiting time, ${ }^{56}$ diagnosis and treatment time, doctor-patient 
relationship, ${ }^{57}$ doctors' service attitudes, medical costs, and hospital environment all affect patient satisfaction.

Different satisfaction subtypes varied considerably with outpatients' sociodemographic characteristics. First, men were almost always more satisfied with various factors than women. It can be interpreted that women have somewhat more meticulous requirements and demands, and that they are more sensitive to high medical costs. ${ }^{31}$ However, it might also be attributed to poorer health services for women; this last possibility was not investigated in this study, meaning that further studies on the quality of health services provided to women are necessary.

Second, medical staff tended to be more satisfied overall than outpatients of other occupations, which is likely because medical staff have a more profound comprehension of medical services, behaviors, and burdens of other medical staff.

Third, outpatients living in the People's Republic of China had higher satisfaction than those living abroad. Longterm living in the People's Republic of China likely helps outpatients better understand the health delivery system in the People's Republic of China, thereby promoting greater tolerance and increasing their satisfaction.

Fourth, and rather surprisingly, young and middle-aged adults tended to have lower odds of high satisfaction than older adults. This is possibly because younger people tend to receive more medical information and have higher expectations and more requirements. In contrast, the elderly trust in medical staff more and are more dependent on them. Therefore, the large gap between expectations and reality might cause young people to show decreased satisfaction than older adults. This is in line with previous findings from the UK, ${ }^{58}$ France, ${ }^{23}$ and the US. ${ }^{21}$ However, it must be noted that some of the outpatients in the youngest group ( $\leq 20$ years old) who participated in this study were too young to complete the questionnaires on their own; therefore, their parents or relatives had to help them. As such, it is possible that the results for outpatient satisfaction of the youngest age group were affected by the attitudes of their middle-aged parents. This should be further explored in future studies.

Fifth, low-income outpatients ( $<2,000$ RMB monthly) had greater odds of high satisfaction than did those with high incomes ( $\geq 10,000 \mathrm{RMB}$ monthly). Low-income outpatients likely have lower expectations regarding medical care, and often their only goal is recovery from their disease. Conversely, high-income outpatients concentrate more on medical quality and their own feelings, which may lead to a lower degree of satisfaction.
Sixth, married outpatients had greater odds of high satisfaction than those who were divorced or widowed. We believe that this is because married individuals have greater life satisfaction and social support and lower economic burdens. Similar results regarding this were noted in a study in Australia. ${ }^{59}$

Finally, workers tended to have low satisfaction with medical costs. According to the sixth survey on national employees, the wages of $72.4 \%$ of workers were lower than average wages of the whole country, and $24.5 \%$ of workers earned $<700$ RMB every month. ${ }^{60}$ Thus, workers often have heavier economic burdens and are more sensitive to medical costs, leading to a lower satisfaction with the same.

\section{Limitation}

There are some limitations of this study. First, the questionnaire focused on the core aspects of outpatient satisfaction; thus, there are some aspects that were not included, such as satisfaction with hospital locations and participation in medical decisions. Second, the survey participants were not stratified by different types of diseases, which will be addressed in a future study. Third, the current survey mainly concentrated on subjective outpatient satisfaction; thus, we lack information on the reality of the health services in these hospitals (although this will be gathered at a later date). Fourth, surveys on the youngest outpatients, especially children, require further improvement, as there are current deficiencies in the survey methods, communication and explanation of the survey's contents to children, and the objectivity of children's responses; these should be explicitly explored and clarified in a future study.

\section{Conclusion}

This study found that the current outpatient satisfaction in tertiary hospitals in Shanghai needs further improvement. These results additionally offer some suggestions for tertiary hospitals in similarly developed areas around the world: for instance, medical staff should pay more attention to outpatient sociodemographic characteristics, especially outpatients who are female, young, divorced, or widowed, in the high-income group, and living abroad. Medical staff should consider each individual's needs, although they must still offer the same quality of services to everyone, suggesting that the only way they can specifically address each patient's needs is by changing the way they talk or explain the situation to the patient. Ultimately, we suggest that tertiary hospitals should provide more support in the management of doctors, medical costs, and time. 


\section{Acknowledgments}

The project was supported by the National Natural Science Foundation of China (71233008, 71303248, 91224005), Important Disease Joint Research Project in Health Systems of Shanghai (2013ZYJB0006), and Military Health Support Strategy and Key Technology Research for special injuries in the South China Sea Region (AWS12J002).

\section{Disclosure}

The authors report no conflicts of interest in this work.

\section{References}

1. Leach CJ, Mandy A, Hankins M, et al. Patients' expectations of private osteopathic care in the UK: a national survey of patients. BMC Complement Altern Med. 2013;13(1):122.

2. Bowling A, Rowe G, Lambert N, et al. The measurement of patients' expectations for health care: a review and psychometric testing of a measure of patients' expectations. Health Technol Assess. 2012;16(30):i-xii.

3. Kleefstra S, Kool R, Veldkamp C, et al. A core questionnaire for the assessment of patient satisfaction in academic hospitals in The Netherlands: development and first results in a nationwide study. Qual Saf Health Care. 2010;19(5):e24-e24.

4. Coulter A. Can patients assess the quality of health care? Br Med J.2006; 333(7557):1-2.

5. Miao FH, Ma ZQ, Ma XY. The importance of hospital quality management of outpatient services. Chin J Mod Hosp Manage. 2011;9(005): $71-72$.

6. Chinese doctors are under threat. Lancet. 2010;376(9742):657.

7. Yu Q, Wang XH, Chen YJ, Zhang SZ, Yu CY, Gu Y. Studying on the progress of research in patients' satisfaction on medical services and its problems. Chin. Health Serv Manage. 2015;32(2):105-107.

8. Partinico $\mathrm{M}$, Corà $\mathrm{A}$, Ghisi $\mathrm{M}$, Ouimet $\mathrm{AJ}$, Visentin $\mathrm{M}$, Group Q. A new Italian questionnaire to assess caregivers of cancer patients' satisfaction with palliative care: multicenter validation of the post mortem questionnaire-short form. J Pain Symptom Manage. 2014;47(2): 298-306.

9. Koksvik HS, Hagen KB, Rødevand E, Mowinckel P, Kvien TK, Zangi HA. Patient satisfaction with nursing consultations in a rheumatology outpatient clinic: a 21-month randomised controlled trial in patients with inflammatory arthritides. Ann Rheum Dis. 2013;72(6):836-843.

10. Mohd A, Chakravarty A. Patient satisfaction with services of the outpatient department. Med J Armed Forces India. 2014;70(3):237-242.

11. Salin S, Kaunonen M, Aalto P. Explaining patient satisfaction with outpatient care using data-based nurse staffing indicators. J Nurs Admin. 2012;42(12):592-597.

12. Feldman M, Golak E. Continuity of care in psychiatric outpatient practice: effect on patient satisfaction. Eur Psychiatr. 2015;30:1916.

13. Christen RN, Alder J, Bitzer J. Gender differences in physicians' communicative skills and their influence on patient satisfaction in gynaecological outpatient consultations. Soc Sci Med. 2008;66(7):1474-1483.

14. Andrade CC, Lima ML, Pereira CR, Fornara F, Bonaiuto M. Inpatients' and outpatients' satisfaction: the mediating role of perceived quality of physical and social environment. Health Place. 2013;21:122-132.

15. Hulme A, Gan A, Beena M, Ejikeme C, Narayan S. Is patient satisfaction in ENT outpatient department influenced by clinic waiting time? Int J Surg. 2013;8(11):639-640.

16. Barak Y, Szor H, Kimhi R, Kam E, Mester R, Elizur A. Survey of patient satisfaction in adult psychiatric outpatient clinics. Eur Psychiatr. 2001; 16(2):131-133.

17. Moore A, Balaji N. Outpatient satisfaction in ENT; central vs peripheral clinics. Int J Surg. 2010;8(7):573.

18. Liew H-P, Gardner S. Determinants of patient satisfaction with outpatient care in Indonesia: a conjoint analysis approach. Health Policy Technol. 2014;3(4):306-313.
19. Wei J, Shen L, Yang H-B, et al. Development and validation of a Chinese outpatient satisfaction questionnaire: evidence from 46 public general hospitals and 5151 outpatients. Public Health. 2015;129(11): $1523-1529$.

20. Sharf SE, Hornback A. Improving patient satisfaction in the outpatient BMT clinic setting. Biol Blood Marrow Transplant. 2013;2(19): S354

21. Tehrani AB, Feldman SR, Camacho FT, Balkrishnan R. Patient satisfaction with outpatient medical care in the United States. Health Outcomes Res Med. 2011;2(4):e197-e202.

22. Gupta D, Rodeghier M, Lis CG. Patient satisfaction with service quality as a predictor of survival outcomes in breast cancer. Support Care Cancer. 2014;22(1):129-134.

23. Nguyen TVF, Bosset J-F, Monnier A, et al. Determinants of patient satisfaction in ambulatory oncology: a cross sectional study based on the OUT-PATSAT35 questionnaire. BMC Cancer. 2011;11(1):526.

24. Wallberg S, Gustafsson E, Bergenmar M. High level of patient satisfaction with nurse-led care in oncology outpatient clinics - report from two surveys. Eur J Cancer. 2011;47:S304.

25. Patel I, Chang J, Srivastava J, Feldman S, Levender M, Balkrishnan R. Patient satisfaction with obstetricians and gynecologists compared with other specialties: analysis of US self-reported survey data. Patient Relat Outcome Meas. 2011;2:21.

26. Bhargava A, Thakur A, Mishra B, Taneja J, Dogra V, Loomba P. Patient satisfaction survey of microbiological tests done in GB Pant Hospital. Int J Health Care Qual Assur. 2012;25(7):555-564.

27. Gulbrandsen P, Benth JŠ, Dahl FA, Jensen BF, Finset A, Hall JA. Specialist physicians' sensitivity to patient affect and satisfaction. Med Care. 2012;50(4):290-293.

28. Liu CH. Development of patient satisfaction research. Med Inform. 2013;26(4):567-568.

29. Li WH, Wu MF. The current situation and existing problems of patient satisfaction survey. Nurs Res. 2010;24(7):1791-1792.

30. Ying J. Analysis of difficulties in patient satisfaction evaluation. Chin $J$ Hosp Admin. 2008;24(7):437-440.

31. Teng ZX, Zhang AL, Lan YC. Influence and its mechanism of individual factors on outpatient satisfaction. Chin J Health Stat. 2011;28(3): 283-285.

32. GuangYu W. Model and empirical analysis of patient satisfaction. Chin $J$ Health Stat. 2006;23(6):518-520.

33. Sheng L, Jinlan L, Wenjun S. Analysis of influencing factors of outpatient satisfaction. Chin J Hosp Admin. 2006;22(10):683-684.

34. Liao HQ, Zen XY, Ren YQ, Zen QX. Analysis of outpatient satisfaction and influencing factors in a certain hospital of Shenzhen. Chin J Health Stat. 2010;27(4):375-376.

35. Wang CM. Survey and analysis of outpatient satisfaction. $J$ North Pharm. 2013;10(12):138-139.

36. Wang WY. Multivariate analysis on satisfaction with health care services of outpatients. Occup Health. 2010;26(1):92-94.

37. Wang CS. The current situation and future development of Chinese nursing reform. J Nurs Manag. 2002;1:1-3

38. Wei C, Wang JR, Zhang LM. The method and effect of multi-level training and assessment of nurses. J Nurs Admin. 2006;6(6):7-9.

39. Huang ZX. Establishment and implementation of nursing performance evaluation standards. J Nurses Train. 2011;26(1):13-14.

40. Shaofeng L. Implementation and effect evaluation of the performance evaluation in the high-quality nursing service. Today Nurse. 2012; (12): 190 .

41. Fen FL, Wu ZJ, Cai YP, Guo Q. Current situation and development strategy of "diagnosis and treatment registration in community". Health Econ Res. 2014;5:010.

42. Zhang QJ, Li M, Zhou Y, Wan XX, Zhou XM. Improving the influence of pre-diagnosis services on outpatient satisfaction. Med Inform. 2015;28(6):28.

43. Zhao Y. Influence of the improvement of pre-diagnosis service quality on patient satisfaction. Chin J Pract Nurs. 2012;28(010):33-34.

44. Li YH. The role and management of pre-diagnosis services. Med Inform. 2013;26(14):28-29. 
45. The Innovation Center for Social Risk Governance in Health [webpage on the Internet]. The Latest Report on Doctor-Patient Conflicts; 2015. Available from: http://srghealth.fudan.edu.cn/a/news/2015/0527/244. html. Accessed August 3, 2015.

46. Li CY, Liu H. An empirical study of medical service attitudes of doctors. Med Philos. 2014;35(10):41-45.

47. Jianli Z. Public hospital performance evaluation indicator system and evaluation system design [D]. J Huazhong Univ Sci Technol. 2012; 5(04):913.

48. Wu JJ [webpage on the Internet]. Ensure At Least 10 Minutes for Doctor-Patient Communication; 2013. Available from: http:/epaper. dfdaily.com/dfzb/html/2013-12/12/content_845288.htm. Accessed March 19, 2015

49. Xu LH. Study on mechanism of medical cost control based on international comparison. China Bus. 2011;4:3-6.

50. Bitzer EM, Volkmer S, Petrucci M, Weissenrieder N, Dierks M-L. Patient satisfaction in pediatric outpatient settings from the parents' perspective-the child ZAP: a psychometrically validated standardized questionnaire. BMC Health Serv Res. 2012;12(1):347.

51. Li DS. Principle of hospital environment afforestation and introduction of humanity. Real Estate Biweekly. 2013;(14):230.

52. Qiao WY. Hospital environment and nursing effect. Chin. J Mod Drug Appl. 2012;6(5):135-136.

53. National Health and Family Planning Commission of the People's Republic of China. Chinese Health Statistical Year Book 2013. Chinese Peking Union Medical College Press; Beijing: 2013.
54. SHYB [webpage on the Internet]. Shanghai Basic Medical Insurance System for Urban Employees; 2014. Available from: http://www.shyb. gov.cn/xxcx/yb02.html. Accessed March 19, 2015

55. Kisa K, Kawabata H, Itou T, Nishimoto N, Maezawa M. Survey of patient and physician satisfaction regarding patient-centered outpatient consultations in Japan. Intern Med. 2011;50(13):1403-1408.

56. Boudreaux ED, Ary RD, Mandry CV, McCabe B. Determinants of patient satisfaction in a large, municipal ED: the role of demographic variables, visit characteristics, and patient perceptions. Am J Emerg Med. 2000;18(4):394-400.

57. Anim-Somuah K, Brailsford FE, Luces C, Bodger K. Satisfaction with healthcare in outpatients with gastrointestinal diseases: validation of an instrument and influence of patient characteristics on ratings. Gastroenterology. 2010;138(5):482.

58. Bowling A, Rowe G, McKee M. Patients' experiences of their healthcare in relation to their expectations and satisfaction: a population survey. J R Soc Med. 2013;106(4):143-149.

59. Aziz Z, Chong NJ. A satisfaction survey of opioid-dependent patients with methadone maintenance treatment. J Subst Abuse Treat. 2015;53: 47-51.

60. Liang KY. Discussion on urban worker incomes in the view of distribution. J Changbai. 2010;150(6):150. 


\section{Supplementary material Outpatient satisfaction survey items of the questionnaire}

1. Sex (male; female)

2. Occupation (student; worker; farmer; retiree; civil servant; medical staff; military personnel; other)

3. Age (years) $(<20 ; 20-29 ; 30-39 ; 40-49 ; 50-59 ; \geq 60)$

4. Monthly income $(<2,000 ; 2,000-4,999 ; 5,000-7,999$; 8,000-9,999; $\geq 10,000)$

5. Residence (Shanghai; other areas of the People's Republic of China; abroad)

6. Marital status (married; single; divorced; widowed)

7. Are you satisfied with hospital environment? (Very dissatisfied; dissatisfied; moderate; satisfied; very satisfied)

8. Are you satisfied with medical costs? (Very dissatisfied; dissatisfied; moderate; satisfied; very satisfied)

9. Are you satisfied with waiting time? (Very dissatisfied; dissatisfied; moderate; satisfied; very satisfied)

10. Are you satisfied with service attitudes of doctors? (Very dissatisfied; dissatisfied; moderate; satisfied; very satisfied)
11. Are you satisfied with diagnosis and treatment time? (Very dissatisfied; dissatisfied; moderate; satisfied; very satisfied)

12. Are you satisfied with your medical needs being met by doctors? (Very dissatisfied; dissatisfied; moderate; satisfied; very satisfied)

13. Are you satisfied with prescriptions? (Very dissatisfied; dissatisfied; moderate; satisfied; very satisfied)

14. Are you satisfied with nurses at prediagnosis counters? (Very dissatisfied; dissatisfied; moderate; satisfied; very satisfied)

15. Are you satisfied with nurses in the waiting room? (Very dissatisfied; dissatisfied; moderate; satisfied; very satisfied)

16. Are you satisfied with the overall situation (including all aspects during the whole health care process)? (Very dissatisfied; dissatisfied; moderate; satisfied; very satisfied)

\section{Publish your work in this journal}

Patient Preference and Adherence is an international, peer-reviewed, open access journal that focuses on the growing importance of patient preference and adherence throughout the therapeutic continuum. Patient satisfaction, acceptability, quality of life, compliance, persistence and their role in developing new therapeutic modalities and compounds to optimize clinical outcomes for existing disease states are major areas of interest for the journal. This journal has been accepted for indexing on PubMed Central. The manuscript management system is completely online and includes a very quick and fair peer-review system, which is all easy to use. Visit http://www dovepress.com/testimonials.php to read real quotes from published authors. 